Louisiana State University

LSU Digital Commons

8-1-2011

\title{
Up-regulation of P-glycoprotein reduces intracellular accumulation of beta amyloid: Investigation of P-glycoprotein as a novel therapeutic target for Alzheimer's disease
}

\author{
Alaa H. Abuznait \\ University of Louisiana at Monroe \\ Courtney Cain \\ Pennington Biomedical Research Center \\ Drury Ingram \\ Pennington Biomedical Research Center \\ David Burk \\ Pennington Biomedical Research Center \\ Amal Kaddoumi \\ University of Louisiana at Monroe
}

Follow this and additional works at: https://digitalcommons.Isu.edu/biosci_pubs

\section{Recommended Citation}

Abuznait, A., Cain, C., Ingram, D., Burk, D., \& Kaddoumi, A. (2011). Up-regulation of P-glycoprotein reduces intracellular accumulation of beta amyloid: Investigation of P-glycoprotein as a novel therapeutic target for Alzheimer's disease. Journal of Pharmacy and Pharmacology, 63 (8), 1111-1118. https://doi.org/ 10.1111/j.2042-7158.2011.01309.x

This Article is brought to you for free and open access by the Department of Biological Sciences at LSU Digital Commons. It has been accepted for inclusion in Faculty Publications by an authorized administrator of LSU Digital Commons. For more information, please contact ir@lsu.edu. 


\title{
Up-regulation of P-glycoprotein reduces intracellular accumulation of beta amyloid: investigation of P-glycoprotein as a novel therapeutic target for Alzheimer's disease
}

\author{
Alaa H. Abuznait ${ }^{\mathrm{a}}$, Courtney Cain ${ }^{\mathrm{b}}$, Drury Ingram $^{\mathrm{b}}$, David Burk ${ }^{\mathrm{b}}$, and Amal Kaddoumi ${ }^{\mathrm{a}}$ \\ ${ }^{a}$ Department of Basic Pharmaceutical Sciences, College of Pharmacy, University of Louisiana at \\ Monroe, Monroe \\ ${ }^{b}$ Cell Biology and Bioimaging Core, Pennington Biomedical Research Center, Baton Rouge, LA, \\ USA
}

\begin{abstract}
Objectives-Several studies have suggested the efflux transporter P-glycoprotein (P-gp) to play a role in the etiology of Alzheimer's disease through the clearance of amyloid beta $(A \beta)$ from the brain. In this study, we aimed to investigate the possibility of P-gp as a potential therapeutic target for Alzheimer's disease by examining the impact of P-gp up-regulation on the clearance of A $\beta$, a neuropathological hallmark of Alzheimer's disease.
\end{abstract}

Methods-Uptake studies for ${ }^{125}$ I-radiolabelled $A \beta_{1-40}$, and fluorescent immunostaining technique for P-gp and fluorescent imaging of $A \beta_{1-40}$ were carried out in LS-180 cells following treatment with drugs known to induce P-gp expression.

Key findings-Approximately $10-35 \%$ decrease in ${ }^{125} \mathrm{I}-\mathrm{A} \beta_{1-40}$ intracellular accumulation was observed in cells treated with rifampicin, dexamethasone, caffeine, verapamil, hyperforin, $\beta$ estradiol and pentylenetetrazole compared with control. Also, fluorescent micrographs showed an inverse relationship between levels of P-gp expression and 5-carboxyfluorescein labelled A $\beta$ $\left(\right.$ FAM-A $\left.\beta_{1-40}\right)$ intracellular accumulation. Quantitative analysis of the micrographs revealed that the results were consistent with those of the uptake studies using ${ }^{125} \mathrm{I}-\mathrm{A} \beta_{1-40}$.

Conclusions-The investigated drugs were able to improve the efflux of $A \beta_{1-40}$ from the cells via P-gp up-regulation compared with control. Our results elucidate the importance of targeting $\mathrm{A} \beta$ clearance via P-gp up-regulation, which will be effective in slowing or halting the progression of Alzheimer's disease.

\section{Keywords}

Alzheimer's disease; beta amyloid; clearance; P-glycoprotein; up-regulation

\section{Introduction}

\begin{abstract}
Alzheimer's disease, a major cause of dementia, is a significant health care problem with about 5.3 million people currently affected in the USA. With the aging of the American population, projections suggest that by 2025, about 12 million Americans will suffer from
\end{abstract}

JPP @ 2011 Royal Pharmaceutical Society

Correspondence Amal Kaddoumi, College of Pharmacy, University of Louisiana at Monroe, 1800 Bienville Dr, Monroe, LA 71201, USA.kaddoumi@ulm.edu.

Conflict of interest The Author(s) declare(s) that they have no conflicts of interest to disclose. 
this disease. ${ }^{[1]}$ Aging is considered the major risk factor of Alzheimer's disease, which is characterized pathologically by the accumulation of tangles and senile plaques in the brain. Senile plaques are composed of beta amyloid peptides $(A \beta) .^{[2]}$

Significant efforts have been made to elucidate the mechanisms responsible for A $\beta$ accumulation in the brain of Alzheimer's patients. Among such mechanisms is the increased level of $A \beta$ as a result of its faulty clearance across the blood-brain barrier (BBB). ${ }^{[3]}$ Continuous removal of $A \beta$ from the CNS is important for preventing potentially neurotoxic $\mathrm{A} \beta$ accumulation. $\mathrm{P}$-glycoprotein (P-gp) has been reported to play a role in $\mathrm{A} \beta$ clearance at the BBB. ${ }^{[4-6]}$ Reduced expression of P-gp at the BBB has been observed during normal aging and in Alzheimer's patients. ${ }^{[5,7]}$

P-gp, the product of $M D R I$ gene, is perhaps the best-known and studied efflux transporter which, under normal physiological conditions, is widely expressed in barrier and excretory tissues. ${ }^{[8]} \mathrm{P}$-gp is highly expressed on the luminal membrane of the endothelial cells at the BBB. ${ }^{[9]}$ At the BBB, P-gp serves as a defence mechanism against a wide spectrum of nonpolar therapeutic drugs and xenobiotics. ${ }^{[10]}$ While its endogenous function is not fully understood, the expression pattern of P-gp has recently been suggested to play a key role in the etiology of Alzheimer's disease, ${ }^{[4]}$ and has been shown to play substantial role in $A \beta$ levels in the brain. ${ }^{[4-6]}$ In-vitro binding studies showed that efflux of $A \beta_{1-40}$ is mediated by $\mathrm{P}$-gp as a result of direct interaction between $\mathrm{A} \beta$ and P-gp. ${ }^{[11]}$ These results were confirmed in cell culture experiments using MDRI-transfected polarized kidney epithelial cells (LLCPK1). ${ }^{[6]}$ Moreover, when labelled $A \beta_{1-40}$ protein was microinjected into the CNS of P-gp knockout mice, the clearance rate of $\mathrm{A} \beta_{1-40}$ across the BBB was reduced to half compared with the wild-type mice. ${ }^{[4]}$

With such a role of P-gp in the clearance of $A \beta$ across the $\mathrm{BBB}$, it is expected that a small decline in its expression or activity, by aging or Alzheimer's disease, will result in decreased clearance of $A \beta$ from the brain, an increase in its level and consequent $A \beta$ deposit. Thus, in the current studies we have hypothesized that up-regulation of the $A \beta$ efflux transporter, $\mathrm{P}-$ gp, will enhance $A \beta$ clearance and decelerate its intracellular accumulation.

In a previous study, we have demonstrated an in-vitro concentration-dependent increase in P-gp expression and activity by various drugs, including rifampicin, dexamethasone, caffeine, verapamil, hyperforin, $\beta$-estradiol and pentylenetetrazole, and ranked these drugs for their potencies to up-regulate P-gp (submitted). Subsequently, in the present study and to demonstrate the possibility of P-gp as potential therapeutic target for Alzheimer's disease, the impact of P-gp in-vitro up-regulation by the above drugs on $A \beta$ cellular accumulation has been investigated in LS-180 cells as a model cell line for the BBB.

The results obtained from this study should furthermore establish the most promising modes of intervention and contribute to drug discovery efforts aimed at selective up-regulation of P-gp as a therapeutic approach for treatment or prevention of Alzheimer's disease.

\section{Materials and Methods}

\section{Materials}

LS-180 cell line and all cell culture reagents were obtained from American Type Culture Collection (Manassas, USA). Rifampicin, dexamethasone, hyperforin, pentylenetetrazole, caffeine, $\beta$-estradiol and verapamil were purchased from Sigma-Aldrich (St Louis, USA). The reagents and supplements required for Western blotting were purchased from Bio-Rad (Hercules, USA). The mouse monoclonal P-gp antibody (C-219) was obtained from Covance Research Products (Dedham, USA). Anti- $\beta$-actin (C-11) and horseradish 
peroxidase (HRP)-labelled secondary antibodies were purchased from Santa Cruz Biotechnology Inc. (Santa Cruz, USA). Normal donkey serum, normal goat serum and Rhodamine Red-X-conjugated AffiniPure donkey anti-mouse IgG $(\mathrm{H}+\mathrm{L})$ secondary antibody against P-gp were purchased from Jackson ImmunoResearch Laboratories Inc. (West Grove, USA). Synthetic ${ }^{125}$ I-A $\beta_{1-40}$ (human) was purchased from PerkinElmer Inc. (Waltham, USA). FAM-labelled $\mathrm{A} \beta_{1-40}$ was purchased from AnaSpec, Inc. (Fremont, USA). All other reagents and supplies were purchased from VWR (West Chester, USA).

\section{Cell culture}

LS-180 cells were cultured in RPMI-1640 growth medium supplemented with $10 \%$ fetal bovine serum (FBS), $50 \mathrm{IU} / \mathrm{ml}$ penicillin and $50 \mu \mathrm{g} / \mathrm{ml}$ streptomycin. The cells were grown to confluence in $75-\mathrm{cm}^{2}$ cell culture flasks for $3-6$ days at $37^{\circ} \mathrm{C} / 5 \% \mathrm{CO}_{2}$ and used between passage numbers $5-20$.

\section{Drug treatment of LS-180 for in-vitro induction study}

Induction of P-gp was carried out as follows. Cells were seeded in 10-mm cell culture dishes at a density of $5 \times 10^{6}$ cells/dish and allowed to attach and grow up to $50-60 \%$ confluence. Stock solutions of rifampicin, pentylenetetrazole, $\beta$-estradiol, dexamethasone, hyperforin, verapamil and caffeine were diluted to a final concentration of $50 \mu_{\mathrm{M}}$ (hyperforin, $100 \mathrm{n}_{\mathrm{M}}$ ) in growth medium before use. Forty-eight hours after cell seeding, control and drug-containing media were added to the respective treatment cells. The cells were then incubated for $48 \mathrm{~h}$ at $37^{\circ} \mathrm{C} / 5 \% \mathrm{CO}_{2}$. The media were not renewed for the duration of the experiment.

\section{Western blot analysis of P-gp}

Cellular protein $(16 \mu \mathrm{g})$ was resolved on 7.5\% SDS-polyacrylamide gels and transferred onto nitrocellulose membrane. The monoclonal antibody for P-gp (C-219) and $\beta$-actin (C-11) at dilutions $1: 200$ and $1: 3000$, respectively, were used. For protein detection, the membrane was incubated with HRP-labelled secondary IgG antibody for P-gp (anti-mouse) and $\beta$-actin (anti-goat) at dilution $1: 5000$. The bands were visualized using Pierce chemiluminescence detection kit (Thermo Scientific; Rockford, USA). Quantitative analysis of the immunoreactive bands was performed using Syngene luminescent image analyzer (Scientific Resources Southwest, Inc., Stafford, USA). Three independent Western blotting experiments were carried out for each drug.

\section{In-vitro uptake of ${ }^{125} \mathrm{I}-\mathrm{A} \beta_{1-40}$ in control and treated LS-180 cells}

${ }^{125} \mathrm{I}-\mathrm{A} \beta_{1-40}$ was used after aqueous reconstitution according the manufacturer recommendation to avoid the formation of $A \beta_{1-40}$ oligomer aggregates. ${ }^{[12]}{ }^{125} \mathrm{I}-\mathrm{A} \beta_{1-40}$ uptake in control and treated LS-180 cells was investigated as follows. LS-180 cells were cultured onto 48 -well plates at $5 \times 10^{4}$ cells/well and treated with $50 \mu_{\mathrm{m}}$ of rifampicin, dexamethasone, caffeine, verapamil, $\beta$-estradiol, pentylenetetrazole or $100 \mathrm{n}_{\mathrm{M}}$ of hyperforin, as described above. The medium was aspirated and the cells were washed by incubation in fresh growth medium for $4 \mathrm{~h}$. The cells were washed, and then pre-incubated for $30 \mathrm{~min}$ with or without $100 \mu_{\mathrm{M}}$ verapamil as a P-gp inhibitor in transport buffer (in mм: $141 \mathrm{NaCl}, 4$ $\mathrm{KCl}, 2.8 \mathrm{CaCl}_{2}, 1 \mathrm{MgSO}_{4}, 10$ D-glucose and $\left.10 \mathrm{HEPES}\right)$. The activity experiments were started by the addition of $250 \mathrm{nCi} / \mathrm{ml}$ of ${ }^{125} \mathrm{I}-\mathrm{A} \beta_{1-40}$ in transport buffer with or without 100 $\mu_{\mathrm{M}}$ verapamil for $1.0 \mathrm{~h}$ at $37^{\circ} \mathrm{C} / 5 \% \mathrm{CO}_{2}$. The activity experiment was terminated by washing the cells with ice-cold phosphate-buffered saline (PBS). Cells then were lysed for $1.0 \mathrm{~h}$ at $37^{\circ} \mathrm{C}$. Intracellular radioactivity of ${ }^{125} \mathrm{I}-\mathrm{A} \beta_{1-40}$ was measured using Wallac 1470 Wizard Gamma Counter (PerkinElmer Inc.), and the data were normalized for the protein content. Intracellular accumulation of ${ }^{125} \mathrm{I}-\mathrm{A} \beta_{1-40}$ was expressed as percent of the means and standard deviation for the amount of $\mathrm{A} \beta_{1-40}(\mathrm{nCi} / \mathrm{mg}$ protein) detected in treated cells 
compared with control cells, both in the presence and absence of verapamil. For each drug three independent experiments were carried out with four replicates in each experiment.

\section{Immunofluorescence staining of P-gp and fluorescence imaging of FAM-A $\boldsymbol{\beta}_{\mathbf{1}} \mathbf{4 0}$}

To confirm the effect of drug treatment on P-gp and the consequent intracellular accumulation levels of $A \beta$, both protein and peptide expressions were visualized using confocal microscopy following treatment with selected drugs, including rifampicin, caffeine, verapamil and $\beta$-estradiol. LS- 180 cells $\left(5 \times 10^{4}\right)$ were seeded on 35 -mm poly-d-lysinecoated glass bottom plates (MatTek Corporation, Ashland, USA) and treated with $50 \mu_{\mathrm{m}}$ of rifampicin, caffeine, verapamil or $\beta$-estradiol as described above. After $48 \mathrm{~h}$, the cells were washed with PBS and incubated with $500 \mathrm{n}_{\mathrm{M}}$ of FAM-labelled $\mathrm{A} \beta_{1-40}$ in serum-free medium for $1.0 \mathrm{~h}$. The cells were then washed with PBS, fixed with $4 \%$ formaldehyde and blocked with $10 \%$ of normal donkey and goat sera. This step was followed by overnight incubation at $4{ }^{\circ} \mathrm{C}$ with a $1: 50$ dilution of primary antibody against P-gp in solution composed of $1 \%$ normal donkey and goat sera in PBS. The cells were washed with PBS and incubated for 30 min with Rhodamine Red goat anti-mouse secondary antibody at $1: 250$ dilution. Images for P-gp and A $\beta$ were captured using Leica TCS-SP5 inverted confocal microscope equipped with $488 \mathrm{~nm}$ line of Argon Laser (Leica Microsystems Inc., Bannockburn, USA). Negative controls for each treatment that were processed without primary antibody showed negligible background fluorescence (data not shown). P-gp and $\mathrm{A} \beta_{1-40}$ membrane fluorescence for each sample were quantified using ImageJ version 1.44 software (Research Services Branch, NIMH/NIH, Bethesda, USA). This experiment was repeated three times.

\section{Statistical analysis}

Wherever possible, the experimental results were statistically analysed for significant difference using two-tailed Student's $t$-test to evaluate differences between controls and treated groups. $P<0.05$ was considered to be statistically significant.

\section{Results}

\section{In-vitro induction of P-gp expression}

The ability of the investigated drugs to induce P-gp expression was assessed by Western blotting using the C-219 antibody. Figure 1a-1e illustrates the fold increase in P-gp expression obtained following Western blotting in LS-180 cells treated with $50 \mu_{\mathrm{m}}$ of rifampicin, dexamethasone, caffeine, verapamil or $100 \mathrm{n}_{\mathrm{M}}$ hyperforin, and quantified by densitometry of the immunoblots. In addition, and as a representative drug, Figure $1 \mathrm{f}$ illustrates a dose-dependent increase in P-gp expression and activity as a result of verapamil treatment. All investigated drugs resulted in an increase in P-gp expression following $48 \mathrm{~h}$ treatment to different extents. Under the in-vitro cell culture conditions, a 2.7-fold increase in the expression of P-gp protein was observed post-incubation with verapamil while rifampicin increased P-gp expression by 5.6 fold compared with control. Hyperforin showed

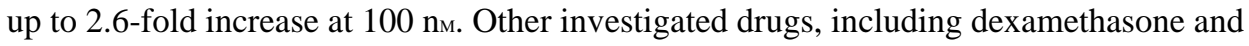
caffeine, resulted in up-regulation of P-gp expression by $70 \%$ and $30 \%$, respectively, when compared with control, while pentylenetetrazole and $\beta$-estradiol increased P-gp expression only by $10 \%$.

\section{Effect of P-gp up-regulation on ${ }^{125} \mathrm{I}-\mathrm{A} \boldsymbol{\beta}_{1-40}$ cellular uptake in vitro}

To determine the consequence of P-gp up-regulation on the accumulation of $A \beta_{1-40}$, the cellular uptake of radiolabelled ${ }^{125} \mathrm{I}-\mathrm{A} \beta_{1-40}$ was evaluated following drug treatment in the presence and absence of $100 \mu_{\mathrm{M}}$ verapamil, a specific P-gp inhibitor. Figure 2 shows the percentage change in the intracellular accumulation of $A \beta_{1-40}$ with and without verapamil in 
treated LS-180 cells compared with control. As a result of P-gp up-regulation by the drugs, the cellular accumulation of $A \beta_{1-40}$ has decreased, and the inhibition of P-gp by verapamil enhanced $\mathrm{A} \beta_{1-40}$ accumulation confirming the specific role of $\mathrm{P}$-gp on $\mathrm{A} \beta_{1-40}$ cellular uptake. This difference in $A \beta_{1-40}$ was more apparent and statistically significant $(P<0.05)$ in cells treated with caffeine, rifampicin, verapamil, $\beta$-estradiol and $100 \mathrm{n}_{\mathrm{M}}$ hyperforin, which resulted in $15-35 \%$ decrease in A $\beta_{1-40}$ cellular uptake (Figure 2). When LS-180 cells treated with these five drugs were co-incubated with verapamil and ${ }^{125} \mathrm{I}-\mathrm{A} \beta_{1-40}$, a significant increase in ${ }^{125} \mathrm{I}-\mathrm{A} \beta_{1-40}$ uptake by $16-32 \%$ was observed $(P<0.05)$. On the other hand, cells treated with dexamethasone and pentylenetetrazole showed moderate decrease in ${ }^{125} \mathrm{I}-\mathrm{A} \beta_{1-40}$ cellular uptake by approximately $10 \%$, and their co-incubation with verapamil increased its intracellular uptake by $8-12 \%$. The above results confirm the role of $\mathrm{P}$-gp in determining $\mathrm{A} \beta_{1-40}$ intracellular levels. The induction of P-gp lowered $\mathrm{A} \beta_{1-40}$ cellular uptake by enhancing its clearance, while the inhibition of P-gp increased $A \beta_{1-40}$ uptake.

\section{Effect of P-gp up-regulation on the intracellular fluorescence intensity of $F A M-A \beta_{1-40}$}

Figure 3a-3c show representative fluorescent micrograph images of P-gp expression of untreated (control, Figure 3a), rifampicin-treated (Figure 3b) and caffeine-treated (Figure 3c) cells captured by TCS-SP5 Leica confocal microscope. Fluorescence of secondary antibody against P-gp was located mainly on the cell membrane, while the fluorescence associated with FAM-A $\beta_{1-40}$ was taken up into the cells (Figure $3 d-3 f$ ). The conjugation of $A \beta$ peptide with FAM fluorophore did not affect the structure and function of the peptide, and the in-vitro uptake of labelled and unlabelled $A \beta$ by cells was similar. ${ }^{[13]}$

Quantitative analysis of P-gp expressed in LS-180 cells showed significant increase in membrane P-gp expression of drug-treated LS-180 compared with control. For example, rifampicin and caffeine resulted in 6.2-fold and 1.5-fold increase, respectively, in P-gp expression compared with control ( $P<0.05$; Figure 3, top bar graph). These results are in agreement with those obtained from Western blotting data (Figure 1). At the same time, this increase in P-gp expression caused by both drugs was accompanied by 43-67\% decrease in the intracellular accumulation of FAM-A $\beta_{1-40}$ when compared with control $(P<0.05$; Figures $3 \mathrm{~d}-3 \mathrm{f}$, bottom bar graph). In addition, treatment with $\beta$-estradiol and verapamil decreased the intracellular accumulation of FAM-A $\beta_{1-40}$ by $28 \%$ and $59 \%$, respectively.

\section{Discussion}

There is compelling evidence that $A \beta$ protein aggregation is an essential early event in Alzheimer's disease pathogenesis. ${ }^{[2]}$ In fact, upon aging, human brain inevitably starts to accumulate $A \beta$ suggesting that the Alzheimer's disease cascade is initiated as a normal consequence of the aging process. However, as compared with healthy aged brains, the accumulation of neurotoxic $A \beta$ in the brains of Alzheimer's patients, although starting slowly, begins to accelerate exponentially after a certain point. ${ }^{[14]}$ This implies that a slight increase in the steady state of $A \beta$ above normal in the brain of Alzheimer's patients may initiate one or multiple vicious processes causing dramatic increase in $A \beta$ levels. ${ }^{[14]}$

LS-180, a human colon adenocarcinoma cell line, ${ }^{[15]}$ is a well characterized in-vitro model utilized in P-gp efflux studies. LS-180 cell line endogenously expresses P-gp and pregnane$\mathrm{X}$-receptor (PXR), which controls expression of P-gp. ${ }^{[16,17]}$ As a result, this cell line is considered a useful tool for the mechanistic investigation of P-gp substrates and is frequently utilized to investigate the effect of P-gp modulation by inhibition or up-regulation on the uptake or clearance of substrate drugs. ${ }^{[18]}$ As most drugs investigated, including rifampicin, dexamethasone, verapamil and hyperforin, have been reported to up-regulate Pgp by activating PXR, ${ }^{[19-22]}$ in the current study LS-180 cell line was chosen as a model for 
the BBB to evaluate the effect of induced expression of P-gp caused by these drugs on the increased efflux, or clearance, of $\mathrm{A} \beta$, a P-gp substrate.

Available experimental data strongly suggest impaired clearance of $A \beta$ across the BBB might largely contribute to the formation of $A \beta$ brain deposits and Alzheimer's disease progression. Also, it has been demonstrated that the efflux transporter P-gp plays a substantial role in the elimination of $A \beta_{1-40}$ and $A \beta_{1-42}$ from the brain across the BBB. ${ }^{[4-6,11]}$ Accordingly, in this study we report the impact of P-gp up-regulation on the intracellular accumulation of $A \beta_{1-40}$ in vitro by rifampicin, dexamethasone, verapamil, caffeine, pentylenetetrazole and $\beta$-estradiol at $50 \mu_{\mathrm{M}}$, and hyperforin at $100 \mathrm{n}_{\mathrm{M}}$ concentrations. As both $\mathrm{A} \beta$ peptide species have been implicated in the pathogenesis of Alzheimer's disease, ${ }^{[23]}$ in this study $A \beta_{1-40}$ was used to investigate our hypothesis.

The examined drugs were particularly investigated as they demonstrated potency to upregulate P-gp expression and activity in a concentration-dependent manner (Figure 1f), and these same drugs have been reported to have positive impact on Alzheimer's disease. For example, in humans, a 3-month course of rifampicin (300 mg p.o.) and doxycycline attenuated the rate of cognitive decline in patients with mild-to-moderate Alzheimer's disease. The authors concluded that such efficacy was unrelated to the antibiotic activity of either drug. ${ }^{[24]}$ In addition, several studies showed caffeine intake as a protective factor for Alzheimer's disease. In a case-controlled study conducted on 54 patients with probable Alzheimer's disease, ${ }^{[25]}$ results showed that patients with Alzheimer's disease had an average daily caffeine intake of $73.9 \pm 97.9 \mathrm{mg}$ during the 20 years that preceded diagnosis of Alzheimer's disease, whereas the controls had an average daily caffeine intake of $198.7 \pm$ $135.7 \mathrm{mg}$ during the corresponding 20 years of their lifetimes. Further, in-vivo studies on mice models of Alzheimer's disease confirmed caffeine's protective role against cognitive impairment and showed that it reduced brain and plasma levels of $A \beta_{1-40} \cdot{ }^{[26,27]}$ Similar positive effects have been reported with hyperforin, which reduced amyloid deposit formation in rats injected with amyloid fibrils in the hippocampus, prevented $\mathrm{A} \beta$-induced neurotoxicity and improved spatial learning acquisition. ${ }^{[28]}$

Pentylenetetrazole, ${ }^{[29]} \beta$-estradiol, ${ }^{[30]}$ verapamil ${ }^{[31]}$ and dexamethasone ${ }^{[32]}$ have also shown anti-Alzheimer's effects in human or animal Alzheimer's disease models. For example, pentylenetetrazole, an old drug once used to treat epilepsy, has been shown to up-regulate P$\mathrm{gp}$ at the BBB of rats treated with $30 \mathrm{mg} / \mathrm{kg}$ for 24 days, where P-gp levels in the brain increased by 1.7 -fold. ${ }^{[33]}$ When pentylenetetrazole $(3 \mathrm{mg} / \mathrm{kg}$, a non-epileptic dose) was administered to a mouse model with Down's syndrome symptoms, Ts65Dn, for 17 days, pentylenetetrazole substantially improved learning and memory in these mice. ${ }^{[29]} \mathrm{Ts} 65 \mathrm{Dn}$ mice demonstrate increased levels of $\mathrm{A} \beta$ in the hippocampus and astrocytic hypertrophy. ${ }^{[29]}$

Collectively, the above summarized data highlight the possible link between the induction of P-gp by the investigated drugs and their associated decreasing risk or protection against Alzheimer's disease. Consequently, in this study we have investigated the hypothesis that $\mathrm{P}$ gp up-regulation enhances $A \beta$ clearance and decelerates $A \beta$ deposition, thus providing effective therapeutic strategy in slowing or halting the progression of Alzheimer's disease. We have shown that exposure of LS-180 cells to rifampicin, verapamil, hyperforin, caffeine, $\beta$-estradiol and, to a lesser extent, pentylenetetrazole and dexamethasone resulted in an increase in P-gp expression ranging from 10 to $460 \%$, and a subsequent decrease in $A \beta_{1-40}$ cellular uptake ranging from 10 to $35 \%$. In addition, P-gp inhibition by verapamil following its up-regulation by the investigated drugs enhanced $A \beta_{1-40}$ cellular uptake by $8-32 \%$. Verapamil has been reported to be a specific competitive inhibitor for P-gp and is commonly used to evaluate the functionality of the P-gp efflux transporter. ${ }^{[34,35]}$ 
The above results confirm that decreased intracellular accumulation of $A \beta_{1-40}$ is associated with P-gp up-regulation caused by the drugs. The investigated drugs demonstrated different potencies in up-regulating P-gp expression (Figure 1). Most of the drugs evaluated in this study up-regulate P-gp via PXR activation, ${ }^{[19-22]}$ where, following drug binding, PXR forms a heterodimer with the retinoid $\mathrm{X}$ receptor (RXR) and subsequently binds to PXR response elements in the 5'-flanking region of the MDR1 gene resulting in transcriptional activation. ${ }^{[36]}$ PXR activation is drug dependent, ${ }^{[36]}$ which may explain the variability in drugs potencies to up-regulate P-gp. Nonetheless, these results support the role of such drugs in enhancing $\mathrm{A} \beta$ clearance as a result of $\mathrm{P}$-gp up-regulation at the $\mathrm{BBB}$, reducing its brain levels and thus improving cognitive function and preventing $A \beta$-induced neurotoxicity. Furthermore, these findings support our hypothesis that targeting P-gp at the BBB as a therapeutic strategy will be beneficial for patients with Alzheimer's disease.

In addition, the results from expression studies of P-gp by confocal microscopy, while somewhat higher, were consistent with those of the uptake studies using radiolabelled ${ }^{125} \mathrm{I}$ $\mathrm{A} \beta_{1-40}$, confirming the inverse relationship between P-gp expression and $\mathrm{A} \beta_{1-40}$ intracellular accumulation. Images of LS- 180 cells demonstrated that rifampicin and caffeine treatments increased P-gp expression by 6.2 and 1.5 fold, respectively. Such increase in $\mathrm{P}$-gp expression was associated with a decrease in FAM-A $\beta_{1-40}$ by both drugs when compared with control. However, the decrease in ${ }^{125} \mathrm{I}-\mathrm{A} \beta_{1-40}$ and FAM-A $\beta_{1-40}$ accumulation in LS-180 cells treated with caffeine (35 and 67\%, respectively) was higher than in those treated with rifampicin (16 and 43\%, respectively) despite the $\sim 6.0$-fold increase in P-gp expression caused by rifampicin compared with the 1.5-fold increase by caffeine. Possible explanations for this observation could be that the increase in P-gp expression caused by rifampicin is not equivalently functional, or the presence of an additional mechanism of $A \beta_{1-40}$ transport across the membrane could be modulated by either treatment. This information is currently under investigation in our laboratory. Similarly, treatment of cells with $\beta$-estradiol and verapamil resulted in a significant decrease in the cellular uptake of ${ }^{125} \mathrm{I}-\mathrm{A} \beta_{1-40}$ (15 and $22 \%$, respectively) and FAM-A $\beta_{1-40}$ (28 and $59 \%$, respectively), while pentelenetetrazole and dexamethasone had a moderate effect on both P-gp expression and ${ }^{125} \mathrm{I}-\mathrm{A} \beta$ cellular uptake. Overall, these results confirm the effect of P-gp up-regulation in enhanced efflux, hence clearance, of $A \beta$ from the cells. Further studies are in progress to evaluate the above drugs in vivo and verify the consequences of such induction on P-gp activity at the BBB and $\mathrm{A} \beta$ clearance.

\section{Conclusions}

Our results showed that in-vitro treatment of LS- 180 cells with rifampicin, caffeine, verapamil, hyperforin and $\beta$-estradiol, and to a lesser extent pentylenetetrazole and dexamethasone, resulted in significant decrease in the intracellular accumulation of $A \beta_{1-40}$ compared with control as a result of P-gp up-regulation. In addition, the results support the link between P-gp up-regulation caused by these drugs and cognitive improvement in patients with Alzheimer's disease. Thus, targeting P-gp could be an effective strategy in slowing or halting the progression of Alzheimer's disease.

\section{Acknowledgments}

The content is solely the responsibility of the authors and does not necessarily represent the official views of the National Center for Research Resources or the National Institutes of Health. In addition, this work utilized the facilities of the Cell Biology and Bioimaging Core that are supported in part by COBRE (NIH P20-RR021945) and NORC (NIH 1P30-DK072476) center grants from the National Institutes of Health.

Funding The project described was supported by Grant Number P20RR016456 from the National Center For Research Resources. 


\section{References}

1. Maslow K. 2010 Alzheimer's disease facts and figures. Alzheimers Dement. 2010; 6:158-194. [PubMed: 20298981]

2. Selkoe DJ. Alzheimer's disease: genes, proteins, and therapy. Physiol Rev. 2001; 81:741-766. [PubMed: 11274343]

3. Zlokovic, BV.; Frangione, B. Transport-clearance hypothesis for Alzheimer's disease and potential therapeutic implications. In: Saido, TC., editor. A $\beta$ Metabolism in Alzheimer's Disease. Landes Bioscience; Georgetown, TX: 2003. p. 114-122.

4. Cirrito JR, et al. P-glycoprotein deficiency at the blood-brain barrier increases amyloid-beta deposition in an Alzheimer disease mouse model. J Clin Invest. 2005; 115:3285-3290. [PubMed: 16239972]

5. Vogelgesang S, et al. Deposition of Alzheimer's beta-amyloid is inversely correlated with Pglycoprotein expression in the brains of elderly non-demented humans. Pharmacogenetics. 2002; 12:535-541. [PubMed: 12360104]

6. Kuhnke D, et al. MDR1-P-Glycoprotein (ABCB1) mediates transport of Alzheimer's amyloid-beta peptides - implications for the mechanisms of Abeta clearance at the blood-brain barrier. Brain Pathol. 2007; 17:347-353. [PubMed: 17610523]

7. Toornvliet R, et al. Effect of age on functional P-glycoprotein in the blood-brain barrier measured by use of (R)-[(11)C]verapamil and positron emission tomography. Clin Pharmacol Ther. 2006; 79:540-548. [PubMed: 16765142]

8. Thiebaut F, et al. Cellular localization of the multidrug-resistance gene product P-glycoprotein in normal human tissues. Proc Natl Acad Sci USA. 1987; 84:7735-7738. [PubMed: 2444983]

9. Beaulieu E, et al. P-glycoprotein is strongly expressed in the luminal membranes of the endothelium of blood vessels in the brain. Biochem J. 1997; 326(Pt 2):539-544. [PubMed: 9291129]

10. Miller DS, et al. Modulation of P-glycoprotein at the blood-brain barrier: opportunities to improve central nervous system pharmacotherapy. Pharmacol Rev. 2008; 60:196-209. [PubMed: 18560012]

11. Lam FC, et al. beta-Amyloid efflux mediated by p-glycoprotein. J Neurochem. 2001; 76:11211128. [PubMed: 11181832]

12. LaRue B, et al. Method for measurement of the blood-brain barrier permeability in the perfused mouse brain: application to amyloid-beta peptide in wild type and Alzheimer's Tg2576 mice. J Neurosci Methods. 2004; 138:233-242. [PubMed: 15325132]

13. Jungbauer LM, et al. Preparation of fluorescently-labeled amyloid-beta peptide assemblies: the effect of fluorophore conjugation on structure and function. J Mol Recognit. 2009; 22:403-413. [PubMed: 19343729]

14. Saido, TC. Overview-Abeta metabolism: from Alzheimer research to brain aging control. In: Saido, TC., editor. A $\beta$ Metabolism in Alzheimer's Disease. Landes Bioscience; Georgetown, TX: 2003. p. 1-16.

15. Tom BH, et al. Human colonic adenocarcinoma cells. I. Establishment and description of a new line. In Vitro. 1976; 12:180-191. [PubMed: 1262041]

16. Ott M, et al. Pregnane X receptor (PXR) regulates P-glycoprotein at the blood-brain barrier: functional similarities between pig and human PXR. J Pharmacol Exp Ther. 2009; 329:141-149. [PubMed: 19147857]

17. Bauer B, et al. Pregnane X receptor up-regulation of P-glycoprotein expression and transport function at the blood-brain barrier. Mol Pharmacol. 2004; 66:413-419. [PubMed: 15322232]

18. Perloff MD, et al. Rapid assessment of P-glycoprotein inhibition and induction in vitro. Pharm Res. 2003; 20:1177-1183. [PubMed: 12948015]

19. Haslam IS, et al. Rifampin and digoxin induction of MDR1 expression and function in human intestinal (T84) epithelial cells. Br J Pharmacol. 2008; 154:246-255. [PubMed: 18332862]

20. Durr D, et al. St John's Wort induces intestinal P-glycoprotein/ MDR1 and intestinal and hepatic CYP3A4. Clin Pharmacol Ther. 2000; 68:598-604. [PubMed: 11180019] 
21. Tannergren C, et al. St John's wort decreases the bioavailability of R- and S-verapamil through induction of the first-pass metabolism. Clin Pharmacol Ther. 2004; 75:298-309. [PubMed: 15060508]

22. Scheer $\mathrm{N}$, et al. In vivo responses of the human and murine pregnane $\mathrm{X}$ receptor to dexamethasone in mice. Drug Metab Dispos. 2010; 38:1046-1053. [PubMed: 20354104]

23. Itkin A, et al. Calcium ions promote formation of amyloid beta-Peptide (1-40) oligomers causally implicated in neuronal toxicity of Alzheimer's disease. PLoS ONE. 2011; 6:e18250. [PubMed: 21464905]

24. Loeb MB, et al. A randomized, controlled trial of doxycycline and rifampin for patients with Alzheimer's disease. J Am Geriatr Soc. 2004; 52:381-387. [PubMed: 14962152]

25. Maia L, de Mendonca A. Does caffeine intake protect from Alzheimer's disease? Eur J Neurol. 2002; 9:377-382. [PubMed: 12099922]

26. Cao C, et al. Caffeine suppresses amyloid-beta levels in plasma and brain of Alzheimer's disease transgenic mice. J Alzheimers Dis. 2009; 17:681-697. [PubMed: 19581723]

27. Arendash GW, et al. Caffeine reverses cognitive impairment and decreases brain amyloid-beta levels in aged Alzheimer's disease mice. J Alzheimers Dis. 2009; 17:661-680. [PubMed: 19581722]

28. Dinamarca MC, et al. Hyperforin prevents beta-amyloid neurotoxicity and spatial memory impairments by disaggregation of Alzheimer's amyloid-beta-deposits. Mol Psychiatry. 2006; 11:1032-1048. [PubMed: 16880827]

29. Fernandez F, et al. Pharmacotherapy for cognitive impairment in a mouse model of Down syndrome. Nat Neurosci. 2007; 10:411-413. [PubMed: 17322876]

30. Pike CJ, et al. Protective actions of sex steroid hormones in Alzheimer's disease. Front Neuroendocrinol. 2009; 30:239-258. [PubMed: 19427328]

31. Popovic M, et al. Neuroprotective effect of chronic verapamil treatment on cognitive and noncognitive deficits in an experimental Alzheimer's disease in rats. Int J Neurosci. 1997; 92:7993. [PubMed: 9522258]

32. Alisky JM. Intrathecal corticosteroids might slow Alzheimer's disease progression. Neuropsychiatr Dis Treat. 2008; 4:831-833. [PubMed: 19183775]

33. Liu X, et al. Increased P-glycoprotein expression and decreased phenobarbital distribution in the brain of pentylenetetrazole-kindled rats. Neuropharmacology. 2007; 53:657-663. [PubMed: 17845805]

34. Pham YT, et al. Interactions of racemic mefloquine and its enantiomers with P-glycoprotein in an immortalised rat brain capillary endothelial cell line, GPNT. Biochim Biophys Acta. 2000; 1524:212-219. [PubMed: 11113570]

35. Barraud de Lagerie $S$, et al. Cerebral uptake of mefloquine enantiomers with and without the P-gp inhibitor elacridar (GF1210918) in mice. Br J Pharmacol. 2004; 141:1214-1222. [PubMed: 15023856]

36. Ma X, et al. The pregnane X receptor: from bench to bedside. Expert Opin Drug Metab Toxicol. 2008; 4:895-908. [PubMed: 18624678] 


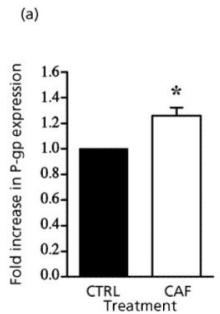

(b)

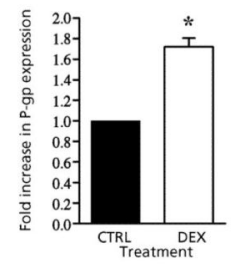

P-gp

$\beta$-Actin

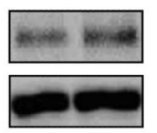

(d)

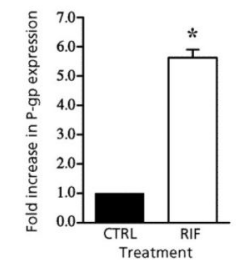

p.9p

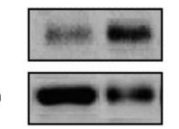

P-gp

$\beta$-Actin

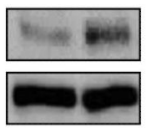

(e)

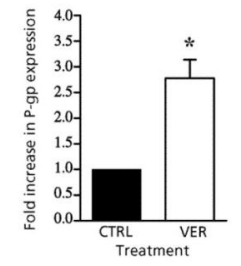

P-gp

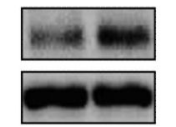

(c)

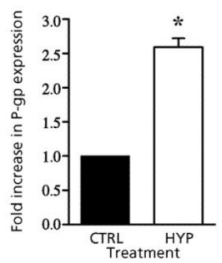

P-gp

$\beta$-Actin

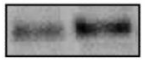

$\square$

(f)

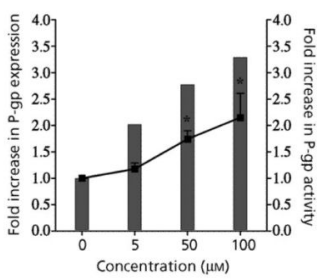

Figure 1.

Representative Western blot and densitometry analysis for the ratio of P-gp to $\beta$-actin expression levels in LS-180 cells treated with (a) $50 \mu \mathrm{m}$ caffeine (CAF) (b) $50 \mu \mathrm{m}$ dexamethasone (DEX) (c) $100 \mathrm{~nm}$ hyperforin (HYP) (d) $50 \mu \mathrm{m}$ rifampicin (RIF) and (e) 50 $\mu \mathrm{m}$ verapamil (VER) compared with control (CTRL). (f) A representative figure for dose dependent increase in P-gp expression (column bars) and activity (line) following treatment with verapamil. The data are expressed as the mean $+\mathrm{SD}, n=3$ independent experiments. $* P \leq 0.05$ vs control. 


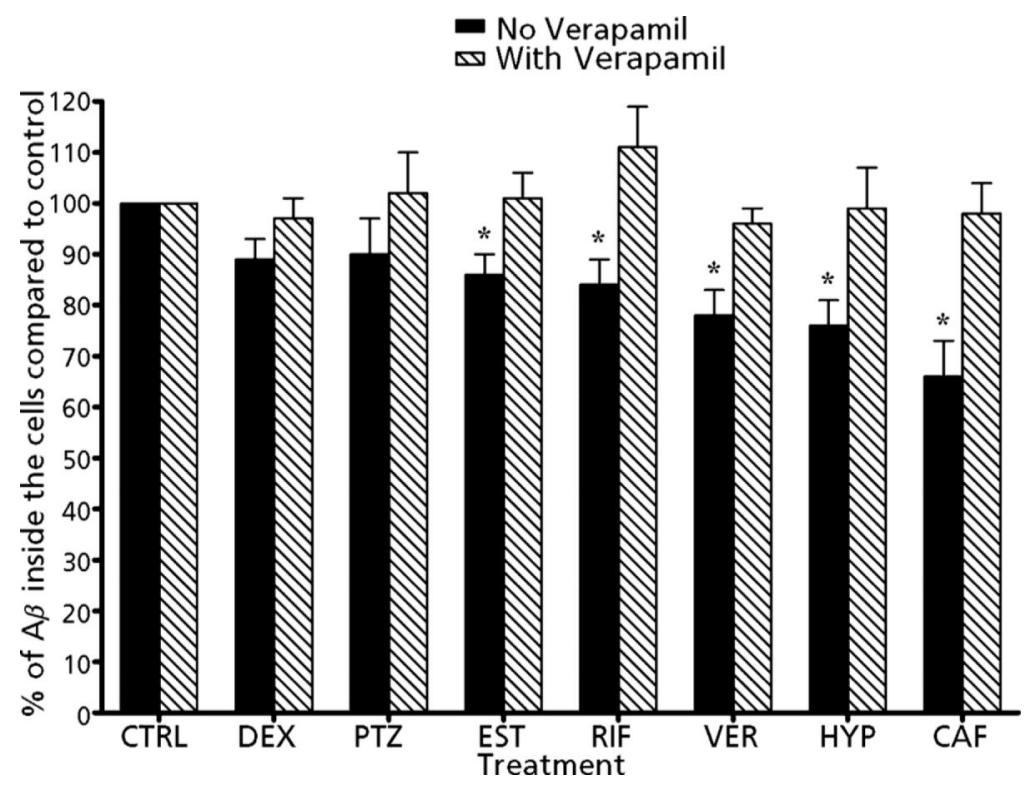

Figure 2.

Effect of treatment of LS-180 cells with rifampicin (RIF), verapamil (VER), dexamethasone (DEX), b-estradiol (EST), pentylenetetrazole (PTZ), hyperforin (HYP) and caffeine (CAF), on the intracellular accumulation of radiolabelled ${ }^{125} \mathrm{I}-\mathrm{A} \beta_{1-40}$. Percent change in the accumulation of $\mathrm{A} \beta_{1-40}$ was evaluated in the presence (dashed bars) and absence (solid bars) of verapamil, a specific P-gp inhibitor. The data are expressed as mean $\pm \mathrm{SD}, n=3$ independent experiments, each drug 4 replicate/experiment. $* P<0.05$. 

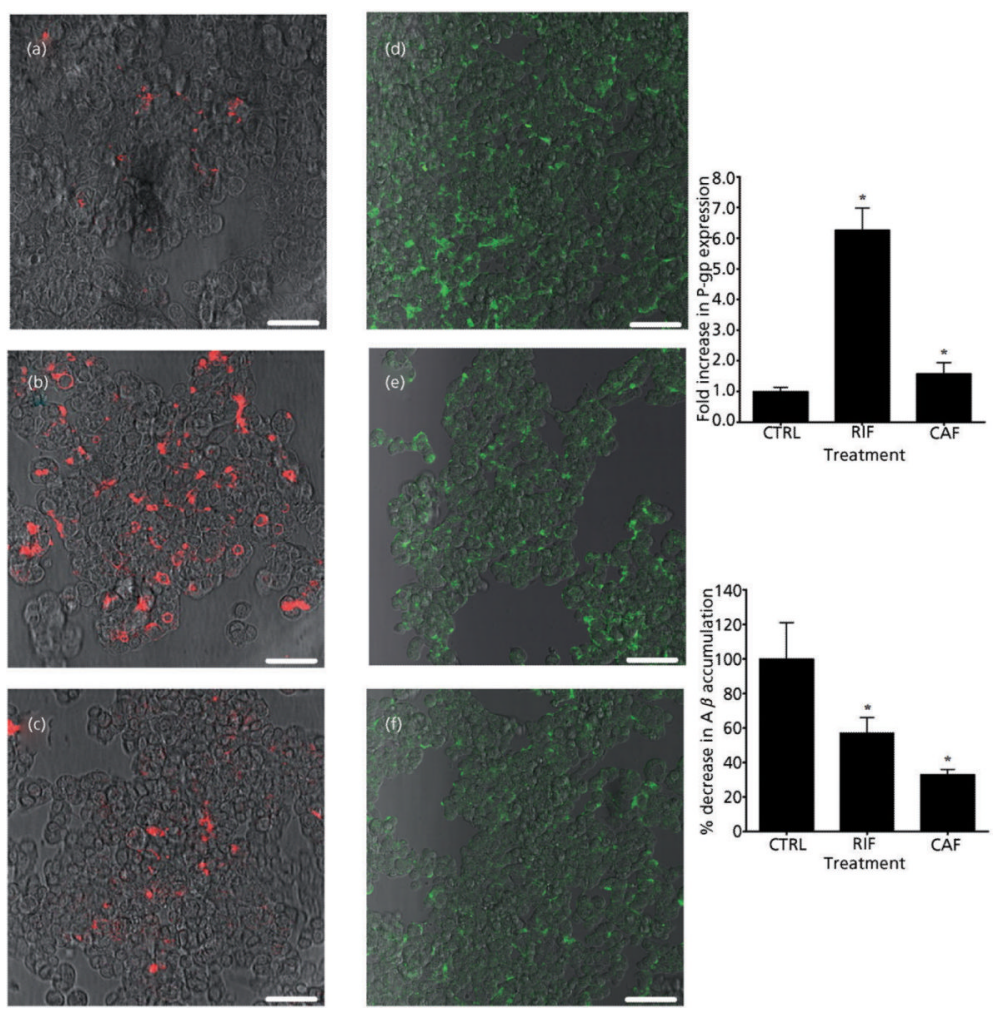

Figure 3.

Representative fluorescent micrographs of P-gp (a, b and c) and FAM-A $\beta_{1-40}$ (d, e and f) for control (a and d) and treated LS-180 cells with rifampicin (b and e) and caffeine (c and f). Quantitative folds change in the P-gp expression and FAM-A $\beta_{1-40}$ intracellular accumulation were measured using ImageJ version 1.44. The data are expressed as mean \pm $\mathrm{SD}, n=3 . * P<0.05$. Scale bar $=25 \mu \mathrm{m}$. 